Angular Momentum" by Rose deal with one and the same such special topic. It is one that is included to some extent in any quantum mechanics text-book, but it has speeial importance in modern work, as these two monographs demonstrate, and is capable of being much expanded instructively and usefully. The difference between the two versions, which is considerable, seems to the reviewer to be just that in Edmonds's work the instructive character strikes on $\theta$ most, in Rose's the useful side. The latter author is himself responsible for a great many important applications of the methods here described, and in this monograph he has succeeded in bringing together in a unified form the mathematical theory underlying these methods as well as an extensive array of its applications, so that to future workers in the field the monograph will undoubtedly serve as a most useful manual. Edmonds in his shorter book lays relatively more emphasis on the formal and conceptual structure of the theory of angular momentum and his book is somewhat more of the nature of an expanded chapter of a text-book on general quantum mechanics. In fact, the Landau-Lifshitz volume contains an admirable chapter on this topic and the fortunate student who learns his quantum mechanics from that work will find himself fully equipped to master the further developments of this monograph. Edmonds's book will undoubtedly be appreciated by workers in the field not least because of the author's commendable policy of listing systematically and fully the great variety of symbols which, unfortunately, are in use to denote the various group theoretical coefficients in which the subject abounds.

\section{N. KEMMER}

\section{PHYSICS FOR THE ELECTRICAL ENGINEER}

Physical Basis for Electrical Engineering

By Prof. Thomas L. Martin, Jr. Pp. xii +410 . (London: Macmillan and Co., Ltd., 1958.) 30s. net.

NOST engineers who have been out of college more than ten years, and many teachers of electrical engineering as well, will find food for thought in this book. Their first reaction may well be of dismay that it is now proposed to teach in a first course in electrical engineering (so the author suggests in his preface) a great deal of physics with which they themselves have only a slight acquaintance. After dismissing in the first two chapters the electromagnetic field in vacuo (from "Vectors and Scalars" via Poisson's and Laplace's equation to the Lorentz transformations and electromagnetic waves) the book goes on to describe modern ideas of atomic and nuclear structure, the structure of metals and of semiconductors, practical semiconductor devices, vacuum and gas tubes, dielectrics (including ferroelectrics) and the theory of magnetic materials.

Closer examination reveals the very real dilemma of the teacher of electrical engineering to-day. Wave-mechanics is carefully excluded from the book, and 'degeneracy' is not to be found in the index. Perhaps this is why the definition of Fermi-level in the text appears so inadequate that it has been supplemented by another definition in an appendix. But should one try to teach all these experimental phenomena, yet firmly refuse to dig in to the solid foundations? If there is not time to teach a student both physics and electrical engineering thoroughly, how valuable is a superficial account of the physics? Yet this is only the physical basis for to-day's electrical engineering-soon it will be yesterday's electrical engineering. (There is nothing here to help us understand the maser or the use of the concept of entropy in communication theory, for example.)

The extent of the work involved in writing a book which covers so wide a field as this book is not to be belittled, especially as it is fairly liberally supplied. with references to original work to enable the reader to pursue his study of any particular point. But one does not need to be a specialist to pick holes in details. Among the dozen or so points noted in a quick reading, there is a suggestion on $p .185$ that conduction in an intrinsic semiconductor commences "at some fairly definite temperature", and on p. 208 we are told there are semiconductor diodes and varistors and transistors, but on p. 210 "semiconductor diodes or varistors" appear to be one and the same. The treatment of space-charge-limited thermionic currents is not happy, and it seems clear that the author has neither read Langmuir's classic papers nor himself tried to measure accurately a 3/2-law characteristic.

To sum up, this book is a bold attempt to provide engineering students with knowledge of what the author considers to be the relevant branches of physics; but even the elementary student deserves a clear and accurate treatment of the topics, and there are some passages which are not up to this standard. D. A. BELL

\section{ANIMAL ECOLOGY}

Animal Ecology

Aims and Methods. By A. Macfadyen. (Zoology Series.) Pp. $x x+264+6$ plates. (London: Sir Isaac Pitman and Sons, Ltd., 1957.) 40s. net.

TPHIS book is difficult to read owing to the use of multitudinous sub-headings which destroy the continuity of the chapters. Partly as a result of this, the treatment of individual subjects tends to be too slight : as soon as some topic begins to grow interesting, it stops short. It would have been better to have selected fewer subjects and dealt with them more thoroughly. Parts of the book are little more than a catalogue. On the other hand, the numerous references which this involves are certainly valuable, though their use is greatly impeded by the unfortunate device of splitting them up into fourteen separate lists at the ends of chapters instead of bringing them together to form a single corpus of literature.

The account of collecting methods (Chapter 6) is very brief and incomplete. Among other omissions, the mercury-vapour trap which has so much revolutionized our knowledge of the distribution and habitats of insects, especially the Lepidoptera, is not mentioned. The description of marking techniques is also too curtailed to be of use. It is condensed into a small paragraph on p. 89 , and no mention is made of the exciting possibilities opened up by marking with radioactive materials (there is brief mention of their use in another connexion). The mathematical procedures to be used in marking - release - recapture work, which might certainly be expected in a book which sets out to include methods, are scarcely touched upon. One has the impression that the chapter on "Biocoenology" could advantageously be replaced 